there was continual pain. Henceforth, I shall do that which appears to me more consonant with sound surgery, viz., to get rid of the extraneous body as soon as it is practicable; in fact, to appiy here the rule that is absolute, regarding the removal of extraneous matters from other parts of the body.

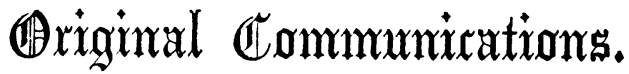

\section{TEN YEARS OF OPERATIVE SURGERY IN THE PROVINCES.}

By Augustin Prichard, Esq., Surgeon, Clifton, Bristol.

\section{IV.-Operations on the Genito.Uninary Apparatus. [Continued from page 974.]}

Stone Cases. This last sub-division of the operations in the genito-urinary system includes lithotomy and lithotrity, and I shall describe them in the following order, viz.: cases of the lateral operation, of the median section (Allarton's), litho. trity, and two cases in the female subject.

CASE CXirix. A. C., aged 11, had been troubled with symptoms of stone all his life, and occasionally had passed small bits of gravel. His symptoms were severe when I saw him, and he had considerable hæmaturia. I performed the lateral operation in the usual way, having given him a dose of castor oil in the previous day, and removed an oxalate of lime calculus weighing a hundred grains. The operation was com. pleted in a minute and a half. He went on without any bad symptoms of importance, the wound was entirely healed in a month, and he was discharged cured.

CASE CI. C. P., aged 8, was suffering severely from the symptoms of stone when I saw him. I performed the lateral operation speedily and easily, and removed a lithic acid stone weighing seven drachms. The water flowed through the wound until the fifth day, when it began to come by the urethra. $\mathrm{He}$ was cured in little more than a fortnight.

Case CI.I. E. H., also aged 8 , was under my care at the same time as the last patient, and I operated upon him on the same day, and removed a very small stone. During the whole of the next day the water flowed through the urethra, but afterwards through the wound. He went out well in about six weeks. The stone was oxalate of lime.

In the first of these two last cases, the stone was very large for so young a subject; and in the second, it was very small ; but both recovered perfectly well, and in about the same time.

CASE CLII. B. G., aged 7, with very severe symptoms of stone. In this operation I entered the groove in the staff at the first cut, and the second penetrated the bladder in the usual lateral method. I removed a large soft phosphatic calculus weighing six drachms. The stone crumbled under the forceps, and I therefore washed out the blood afterwards, and, as there was tolerably free hæmorrhage, I introduced a portion of a gum elastic catheter, and plugged the wound around it with sponge. This stopped the bleeding at once. He went out cured in about four weeks.

The catheter surrounded by the sponge was of very great use in this case, for it stopped the flow of blood, and enabled him to keep the bed dry, by letting the end of the catbeter rest in a dish.

$\mathrm{C}_{\text {ASE }}$ cIII. E. H., aged 34 , a ricketty and strumous little barber, had suffered more or less from stone symptoms all his life, and for five years before I saw him they had been very severe. 'The stone was very easily discovered by the sound. I tried to crush it, but could only touch it with the points of the blades of the lithotrite, and, therefore, was obliged to perform lithotomy.

I used a large straight staff, and cut down at once upon the groove, but when I made the next cut, which should have entered the bladder, I found that it did not pass freely; in fact, the staff had slipped out of the bladder. 'This was fortunately remedied at once by passing a curved staff instead of the other, and it entered readily, and I completed the incision of the prostate. The finger having been introduced into his bladder, the stone did not fall down as usual upon it, although it was, in sounding, always felt near the neck of the bladder, and always in the same spot.

There was extreme difficulty in laying hold of it, and it could only be done by getting an assistant to press very forcibly with the hands in the hypogastric region, and when I had hold of $i$ with the forceps I could neither rotate it nor move it. I therefore broke it with the strong forceps with a screw handle, and extracted it piecemeal. It was evidently adherent at the anterior part. He lost a good deal of blood. The stone was phosphate of lime and magnesia and ammonia, with a nucleus of oxalate of lime, and an external layer of phosphate of ammonia and magnesia, that is, a mulberry calculus inside, then fusible calculus, and then externally triple phosphate, and it weighed twenty drachms and a half. He was nearly an hour under chloroform on the table. As he recovered, which he did without any very troublesome symptoms that could be referred to the operation, he suffered from constipation for sixteen days, and this yielded to an injection of ox-gall, after nearly everything else failed. No water passed through the urethra for thirtyeight days after the operation. He went out in about seven weeks, and lived well and comfortably for some time. Nearly five years have elapsed since the operation, but I heard lately that my patient has recently died.

This case was one of adhesion of a large stone to the anterior surface of the bladder, and presented very great difficulties. The great length of time which elapsed before the water came through the urethra was due to the injury inflicted in the parts by the passage of so many instruments, and the extraction of so large a stone in such rough fragments.

CASE cLIV. J. F, aged 5 years, had very severe symptoms of stone for a few weeks before his admission, having suffered altogether for eight months. He had a very narrow perineum, even for so young a child. I performed the lateral operation, and cut into his bladder without difficulty, and in a short time extracted a lithic acid calculus weighing a hundred grains. There was less bleeding than usual. He was restless the next night, and no water passed from the wound ; and therefore, the next day, I oiled my finger and passed it through the wound, giving an escape to some urine and some small coagula. His respiration was hurried. I treated him with a little stimulus, and some opium in small doses, but he grew worse, and died on the sixth day after the operation. His most prominent symptom was cough and difficulty of breathing.

Post Morten Examivation. The bladder was much thickened, looking like a small uterus; its mucous membrane was ulcerated and red in patches. There was effusion of urine between the bladder and the abdominal parietes, and into the cellular tissue of the pelvis, with a formation of unhealthy pus. There was also acute pleuro-pneumonia of both lungs; the lower lobe of the right lung sunk in water, as did separate portions of the left lung.

The cause of death here was undoubtedly an extravasation of urine into the cellular tissue of the pelvis. 'The section through the prostate did not appear to the finger to be as extensive as it was in some of my former cases, particularly the first (Case cxuIx), where the patient's recovery was uninter rupted. I lost, therefore, in my cases of lateral lithotomy, one patient out of six.

Median Lithotomy. CASE CLv. W. H., aged 11 years, was admitted under my care with symptoms of stone, which hacl existed for nine years. I performed the median section with the fore finger of the left hand in the rectum supporting the staff, and using a sharp pointed knife, the edge directed upwards. I punctured the membranous portion of the urethra and incised it. The finger followed a probe readily through the prostate, and two stones were easily extracted. They weighed about 165 grains, and were composed of lithic acid and lithate of ammonia. The next day the boy had regained the power of holding his water, and some came through the urethra, and he went on perfectly well in every respect until the seventh day, when he had a rigor, and on the next day following an eruption like the nettle rash came out. He became rapidly worse, and died, with symptoms of pyæmia, on the eleventh day after the operation.

Post Mortem Examination. The body had begun to de compose, although the examination took place twelve hours after his death. 'The bladder was thickened, but not unhealthy. The wound in the urethra was a neat clean cut, about three. quarters of an inch in length, extending as far as the prostate, but no further, and all the parts connected with the operation seemed in a satisfactory state.

That the boy died of pyæmia there was the following evidence: pus (in small quantity) in the anterior mediastinum purulent lymph over the pleura of the right side; round deposits of thick pus in and upon both lungs; reddish pus in the left ankle joint, and between the os calcis and astragalus; a 
muddy thick coagulum in the veins of the left leg, and redness of the left femoral vein.

CASE cLVI. G. D., after 56, a carpenter, a tall, stout man was admitted as my patient with very severe symptoms of stone. The case having been published in the Journar. (May 15,1858 ) at length, I need only repeat that upon sounding him it was very difficult to detect the stone; but on operating (by the median section) I removed two soft phosphatic stones, containing soft greenish extraneous substance in their interior, and this turned out to be portions of leek which he had passed into his bladder to relieve retention. He remained my patient for four months, and in that space of time I cut him four times, and removed six stones, and he went out perfectly well on the sixth day after the last operation, and has remained quite well, two years at least having elapsed since that time.

Each of the operations on this man was extremely difficult, owing to the depth of his perineum and his enlarged prostate. I never heard of any other case where the same patient had undergone lithotomy four times, and I have not the least idea that this man could have survived four lateral operations.

CASE cLvir. H., aged about 30 , broke a gum elastic catheter in his urethra three weeks before I saw him. An incision was made, but the foreign substance escaped into the bladder. When I saw him he had, besides the extreme irritation of this body in his bladder, the much more serious complication of extravasated urine into bis scrotum and perineum, with a sloughing wound, and a great state of general collapse. I made the median section, and after a long and painful trial with various instruments, succeeded in laying hold of the bougie, and extracted it. There was little or no hæmorrhage, and from this time the patient improved. He had one or two drawbacks in the form of diarrhœa, but eventually he recovered well.

It has been seen, by some of my former cases, what are the perils of extravasated urine, and when these are added to the risks of a lithotomy operation in a very irritable and depressed condition of the system, it must be admitted that this patient narrowly escaped with his life. It is, in my opinion, very probable that the substitution of the median section for the lateral operation, by not interfering with the deep tissues at the neck of the bladder when the superficial ones were filled with urine and pus, may be considered the saving point in his case.

Lithotrity. CASE clvirr. J. W., aged 44, was admitted under my care suffering from fistula in ano, which had existed for eighteen months ; he also had partial paralysis of his lower extremities, and some difficulty in passing water, due to paralysis of the bladder. Upon drawing off his water one day, one of my pupils discovered that he had a stone in his bladder, but his symptoms were not very urgent, probably because the nerves of sensation supplying the part were as much deadened in sensibility as his motor nerves were in their functions.

At the first operation I seized the stone readily, for his bladder retained the water easily, and crushed it, and then took hold of several pieces and crushed them without any difficulty. The scoop was then introduced, and the water and some debri allowed to escape, but upon withdrawing the scoop I found that a piece of stone had hitched in it and it would not pass into the urethra. There is no contrivance connected with this instrument for the purpose of dislodging a portion of calculus impacted in it, and I was much puzzled, trying various means, probably for twenty minutes, and at last it was dragged through the urethra with some force, causing a discharge of blond. It was a large square piece of stone. A rigor followed this operation, but no other inconvenience. He passed a great many pieces of stone without difficulty, and was relieved in a great measure of the few symptoms he had.

I operated again in twelve days, and crushed three or four portions of the stone with great ease, and this was also followed by the discharge of debris to a considerable extent.

I operated again in little less than a month, crushing three pieces, and a few days afterwards he passed a large bit and many others; the large portion required to be removed by the house surgeon from the orifice of the urethra.

The crushing was repeated after this no less than seven times, and always with the effect of bringing away a consider. able quantity of stone, and he had many pill-boxes full of fragments which he had collected. The treatment was very prolonged, for it was now and then interfered with by attacks of gout, to which he was subject; but ultimately the whole mass was got rid of, and none could be found in the bladder, and his symptoms ceased. He died of cerebral disease some months after he went out, but he had no return of any urinary difficulty.

This patient was an excellent one for a first case of lithotrity, for he had a large urethra and a capacious bladder, and his mucous membrane was very tolerant of the lithotrite and rough stones.

CASE CLIX. R. S., a fine healthy old man, 78 years of age, was under treatment at the same time as the last patient. He had suffered severely from stone, and was willing to undergo any operation.

At the first crushing I found an extremely hard stone, mea. suring, in the diameter by which $I$ held it, an inch and an eighth. I broke it up, and removed some by the scoop, and several pieces passed in the night. The stone was hard, laminated, and composed chiefly of oxalate of lime. Many large pieces came through his urethra, being caught at the orifice, whence they were dislodged, but sometimes with some difficulty. This patient was operated on five times, and at last completely cured, and although he was so old, I have seen him now some years after the operation, walking about actively, and quite cured of his disease.

CASE cLX. J. B., aged 45, was suffering excessively from symptoms of stone when I saw him, for, in addition to the ordinary inconvenience of this malady, he had stricture of the urethra, and formerly had suffered from perineal abscess, leaving a fistulous opening, and, as if this was not a sufficien amount of irritation, his medical attendant had been applying nitrate of silver to the bladder to cure it of the chronic inflam mation, and by this means it had become acute.

I caught and crushed a soft stone with Chamére's smal lithotrite, and found that at two measurements (at each of which it was crushed) it was three-quarters of an inch in diameter. He passed a considerable quantity in the night, and the next day told me that he was "a thousand pounds better." The operation was repeated three times more, und he was then cured, and instead of being a man broken down in health, suffering excessively, and almost sinking from his disease, he is now, six years after the operation, as he has been ever since, a strong and energetic man, able to attend to an active business with comfort.

CASE CLXI. W. I., aged 16 , an unhealthy strumous lad, who had suffered from stone symptoms for nine months, was ad mitted as my patient, and having been encouraged by my former cases, I determined to try lithotrity in him.

After the first crushing he passed a great many pieces, and his sufferings were relieved; but after a second operation, this time under chloroform, although he passed many pieces of stone, he suffered great irritation. This was relieved by barley-water, and a little alkaline medicine, with an opiate at night, and he became better, but there was evidently more stone in the bladder. At his earnest request I let him go home in the country, with the promise to return in three weeks to have his case completed; but after a considerable time, not hearing anything of him, I sent to inquire, and found that he was dead. No particulars of his condition before death were obtained.

I think that this patient's case was really more adapted for lithotomy than lithotrity, and under similar circumstances, I should, for the future, adopt that method; but he seemed more unhealthy in his general condition than the state of the bladder would account for, and I was, therefore, unwilling to run the additional risk of the lateral operation, which was the only cutting operation for stone in vogue with us at that time.

Lithotrity in the Female. CASE cIXIr. M. P., aged 11, had suffered from symptoms of stone all her life, but they had much increased for the few weeks preceding her admission. I operated on her with the most convenient instrument we had at that time, namely Charriere's small lithotrite for the male subject, and crushed a stone of an inch and a quarter's diameter by the direction $I$ held it. No bad symptoms followed; some pieces came away, and a considerable quantity of white and hard crystalline ammonio-phosphate of magnesia. I operated three times more before she was cured, and each pro. ceeding was accompanied by the discharge of débris, and on one occasion by considerable bits of stone. She was dismissed cured.

A peculiarity in this case was the great capacity of the bladder for a girl of 11 years. I once introduced the instrument in my search for the stone, until, from the length, its extremity must have reached to the umbilicus, $;$ but no stone could be found; but, after introducing the catheter and drawing off twenty ounces of water, I found it readily.

Removal of a Foreign Substance from the Female Bladder. CASE cLXIII. J. B., aged 30, was admitted one morning under my care, saying that, as it was hot weather, she got out of bed, and sitting down upon her work-bag, felt something run into and sitting down upon her work-bag, felt something run into
her body. I found a foreign substance in her bladder, which 
turned out to be what she knew it was, the handle of a crochetneedle, and by holding it with a forceps I was enabled to thrust the point into the vagina, and after cutting down upon it to bring it through. She recovered without any further difficulty. The instrument was the ivory handle of a needle, four inches in length, tapering to a sharp point.

REMARKS. I have but few observations to make upon the operations for the removal of stone from the bladder. It is not likely that I shall ever perform the lateral operation again, except upon the dead subject, as a demonstration to the students, for I carnot imagine any circumstances that could induce me to return to it. My own few lateral operations have been much more speedily performed, and have looked much better than the others, and I met with an average share of success in them; but the real question to be considered is the patient's safety, and this is undoubtedly best observed by the median cut. A surgeon would naturally say, at first, that the new operation would do well for small stones, but not for large ones; but now there is ample experience to show that large ones may be removed by this method without injuring the tissues, and with such experience before them, it is surprising that surgical professors should still be found to teach that it is more dangerous to stretch than to cut the prostate.

It is always considered advisable that the patient should have a certain quantity of water in the bladder at the time of the operation, and the simplest plan is to direct them to pass water at a certain time, say one hour, before the time fixed for the operation, and in this way a sufficient quantity is secured.

Now that a short lithotrite is made, and the instruments are more effective, the operation of cutting in the female must become very rarely, if ever, necessary. With a large, short, and dilatable urethra, the circumstances are those which are best adapted for lithotrity.

In these latter operations in the male subject, I have been surprised to find how much better the patients feel from the date of the operation, although but little has escaped; this is because the weight of a broken stone is diffused over a larger surface than the same weight in one piece.

I think that the scoop to draw off the water, and stones, and débris, after an operation, is of no real use; and, according to my experience, it is better to break the stone, and let nature expel the pieces. In the case of an accidental dilemma such as that in which I was placed in one of these operations, viz., with a large piece of stone impacted in the blades of the scoop, it might be detached by the following simple method; which, however, did not strike me until I had dragged a large and rough fragment through the urethra of my patient; but he, fortunately, was not very sensitive in those parts. The plan would be to open the blades as widely as possible, turn the instrument round so that the stone could drop out, and give it a smart tap near the part entering the urethra; and the shock of this blow would inevitably shake off the fragment.

Of the lithotrites in ordinary use, the English ones, as, for example, those made by Weiss, are the strongest and best in many respects; but there is one contrivance connected with the French instruments which is of great value: namely, that when the stone is seized by the French lithotrite, the screwing and crushing may be commenced immediately, by an ingenious mechanism at the handle of the instrument; but, with the English instrument, the surgeon must turn the screw until it travels down to the upper blade of the lithotrite, before the pressure will tell upon the stone. This involves, possibly, an inch of screwing; and I have many times seen a stone slip away in this interval, the surgeon paying more attention to turning the screw than to holding the stone. An AngloFrench lithotrite, combining the advantages of both, would be the best.

I have had some bandages made, which I call my lithotomy straps, intended to supersede the red webbing bandages by which the hands and feet are bound together in these operations. These straps consist of padded leather bracelets fitting to the wrists, and buckling firmly round them ; and some firm leather anklets, of the shape of the elastic bandages for the ankles, which can be buckled on over the ankles. The bracelets have a strong hook on the middle of their palmar aspect, and opposite each onter malleolus is an iron ring. The bracelets and anklets being put on when the patient is in bed, as soon as he is under chloroform, or the staff is introduced, the hooks are passed through the rings, and all is done. He is in like manner relieved from the irksome posture in an equally short time.

\section{REMARKS ON OBSTRUCTION OF THE BOWELS WITH CASES.}

By Edward Copeman, M.D., M.R.C.P., F.R.C.S., Physician to the Norfolk and Norwich Hospital.

[Continued from page $9 \pi 8$.

CASE X. Fatal Obstruction from Stricture of the Rectum. On May 16th, 1855, I was requested to visit a single lady, aged 33, on account of hæmorrhage from the bowels, for which she had for some time been treated by a practitioner in Lon. don without benefit. I believe he was not a regular physician, and had directed her to avoid aperient medicine, and to put up as long as possible with the inconvenierice which she suffered from constipation. I found her general health giving way but she was neither anæmic nor emaciated. Her history was one of long continued constipation; but under the advice she had received, she avoided aperient medicine, and endeavoured to meet the difficulty by limiting the supplies of food, until, in fact, her health had been very much reduced by starvation. I found the rectum completely full of lumpy frecal matter, very capacious, and its mucous membrane loose, and embracing in its folds the scybala which the rectum contained. I hoped that intestinal impaction might be the cause of all her pain and ill health; and prescribed colocynth and henbane in small repeated doses, with the componnd gentian mixture, and an enema as often as might be required. The result of this treatment was the evacuation of large quantities of fæces, emptying the rectum of its contents; but although these measures and an improved state of diet were greatly restorative to her general health, I found on subsequent examination that, at the distance of about a finger's length from the anus, the rectum was contracted to a very small size, and that the opening along the bowel was through a small mamillary projection, surrounded by structure firmer than natural, leading me to fear the existence of scirrhous stricture of the rectum. The calibre of the bowel at the seat of stricture was not much larger than a goose-quill. Still her health improved, and her complexion was not unhealthy or of a colour to indicate the existence of cancerous disease; and, for a length of time, attempts were made by her surgeon in Norwich to dilate the stricture, hoping that it might not be malignant. On one occasion, she con sulted Mr. Fergusson in London, who thought the disease was not malignant, and encouraged further attempts at dilatation. These were attentively and carefully persevered in for a length of time by her surgeon, with varying degrees of suecess. Sometimes the bowels would be sufficiently relieved, and then she was better; at other times there would be obstruction and great distension of the bowels, accompanied with distressing colicky pains. In order to facilitate the dilatation of the stricture, the sphincter ani was divided, and the diseased part brought more within the reach of manipulation. At last, the distension of the bowels became more constant and painful; her strength failed; emaciation became rapidly progressive and although even yet, by means of the introduction of a small tube (No. 12 catheter) and injections, the bowels were sufficiently relieved to prevent death from obstruction alone, it became painfully evident that the vital powers were ebbing fast, under the joint influence of mechanical obstruction, nain, and malignant disease. In the middle of July 1856, she died; and on the 17 th, a post mortem exa. mination was made, which disclosed the following morbid appearances.

The body was extremely emaciated. The abdomen very prominent. The intestines were universally distended. The colon was of an immense size, with longitudinal bands of extraordinary development. The cæcum was very large; and, on tracing the course of the colon, we found that it first passed upwards to the liver, then took a sharp bend downwards to a level with the caput cæci; here it made another curve at an acute angle, and then passed upwards and towards the left side as high as the level of the mamma, whence it again passed downwards as low as the pubes, pushing the rectum to the right of the median line. After this, it took another turn upwards toward the left loin, and then again passed to the left side of the brim of the pelvis, where it became narrowed into a stricture, through which the little finger passed with difficulty. Here the rectum might be said to commence, forming a pouch capable of holding about two pints of fluid, and pushed somewhat to the right by one $c_{i}^{i}$ the coils of the colon; this pouch terminated in a firm stricture, surrounded by a considerable mass of scirrhous structure, about three inches from the anus. The bowels above the stricture contained not only air, bn 